\title{
Overview of Impurity Control and Wall Conditioning in NSTX
}

H.W. Kugel ${ }^{a}$, R. Maingi ${ }^{b}$, W. Wampler ${ }^{a}$, R.E. Barry ${ }^{b}, M$. Bell $^{a}$, W. Blanchard ${ }^{a}$, D. Gates ${ }^{a}$, D. Johnson a , R. Kaita ${ }^{a}$, S. Kaye ${ }^{a}$, R. Maqueda ${ }^{c}$, J. Menard ${ }^{a}$, M.M. Menon ${ }^{\text {, }}$, D. Mueller ${ }^{\mathrm{a}}$, M. Ono ${ }^{\mathrm{a}}$, S. Paul ${ }^{\mathrm{a}}$, Y-K. M. Peng ${ }^{\mathrm{b}}$, R. Raman ${ }^{\mathrm{a}}$, A. Roquemore, C. H. Skinner ${ }^{a}$, S. Sabbaghe, B. Strattona, D. Stutman', J. R. Wilson ${ }^{a}$, S. Zweben ${ }^{a}$, and the NSTX National Research Team

${ }^{a}$ Princeton Plasma Physics Laboratory, Princeton, NJ 08543, USA.

${ }^{b}$ Oak Ridge National Laboratory, Oak Ridge TN, 37831 , USA

${ }^{\circ}$ Los Alamos National Laboratory, Los Alamos, NM, 87545, USA

¿University of Washington, Seattle, WA, 98195, USA

${ }^{\circ}$ Columbia University, New York, NY, 10027, USA

'Johns Hopkins University, Baltimore, MD 21218, USA

${ }^{g}$ Sandia National Laboratories, Albuquerque, NM, 87123, USA

\begin{abstract}
The National Spherical Torus Experiment (NSTX) started plasma operations in February 1999. In the first extended period of experiments, NSTX achieved high current, inner wall limited, double null, and single null plasma discharges, initial Coaxial Helicity Injection, and High Harmonic Fast Wave results. As expected, discharge reproducibility and performance were strongly affected by wall conditions. In this paper, we describe the internal geometry, and initial plasma discharge, impurity control, wall conditioning, erosion, and deposition results.
\end{abstract}




\section{DISCLAIMER}

This report was prepared as an account of work sponsored by an agency of the United States Government. Neither the United States Government nor any agency thereof, nor any of their employees, make any warranty, express or implied, or assumes any legal liability or responsibility for the accuracy, completeness, or usefulness of any information, apparatus, product, or process disclosed, or represents that its use would not infringe privately owned rights. Reference herein to any specific commercial product, process, or service by trade name, trademark, manufacturer, or otherwise does not necessarily constitute or imply its endorsement, recommendation, or favoring by the United States Government or any agency thereof. The views and opinions of authors expressed herein do not necessarily state or reflect those of the United States Government or any agency thereof. 


\section{DISCLAIMER}

Portions of this document may be illegible in electronic image products. Images are produced from the best available original document. 


\section{Introduction}

In February 1999, the National Spherical Torus Experiment (NSTX) achieved first plasma. In the first extended period of experiments, it promptly achieved high plasma current, in inner wall limited, double null, and single null plasma configurations. $130 \mathrm{kA}$ of initial non inductive current generation using $20 \mathrm{kA}$ of Coaxial Helicity Injection ( $\mathrm{CHI}$ ) current has been demonstrated, and indications of electron heating with $2 \mathrm{MW}$ of High Harmonic Fast Wave RF heating (HHFW) have been obtained.

This start-up is the first step in an investigation of the physics principles of lowaspect-ratio Spherical Tori (ST) in a device designed to study non-inductive start-up, current sustainment and profile control, confinement and transport, pressure limits and self driven currents, stability and disruption resilience, and unique scrape-off layer (SOL) and Divertor characteristics.[1,2] These ST principles will be studied in regimes with high temperature, high density, non-inductively sustained high- $\beta_{T}$ discharges ( $40 \%$ ) with high pressure driven current fractions $(\simeq 70 \%)$ which provide possible approaches toward a small, economical, high power ST reactor core.[2]

Fig. 1 shows a partial schematic cross section of NSTX. The device capabilities include $R_{0} \leq 0.85 \mathrm{~m}, \mathrm{a} \leq 0.67 \mathrm{~m}, \mathrm{R} / \mathrm{a} \geq 1.26, \kappa \leq 2.2, \delta<0.5, \mathrm{I}_{\mathrm{p}} \leq 1 \mathrm{MA}, \mathrm{B}_{\mathrm{T}} \leq 0.3 \mathrm{~T}$, and 5 sec maximum pulse length. Copper Passive Stabilizer Plates, graphite power handling surfaces, $5 \mathrm{MW}$ of Neutral Beam heating (Oct. 2000), $6 \mathrm{MW}$ of $30 \mathrm{MHz}$ High Harmonic Fast Wave (HHFW) for heating and current drive at 10-20 $\omega_{\mathrm{ICRF}}$. The $0.2 \mathrm{~m}$ radius Center Column is clad with alternating vertical columns of $1.3 \mathrm{~cm}$ thick graphite (Union Carbide, Type ATJ) tiles between columns of 2-D Carbon Fiber Composite (CFC) (Allied Signal, Type 865-19-4) tiles. The Inner Divertor tiles are $5.1 \mathrm{~cm}$ thick graphite; the Outer Divertor and Passive Stabilizer Plate tiles are $2.5 \mathrm{~cm}$ thick graphite. Shown in Fig. 1 is a unique feature of NSTX: toroidal ceramic insulators, in the top and bottom Divertor gaps, which allows for electrical biasing of the inner and outer vessel for $\mathrm{CHI}$. This configuration enables experiments with Ohmic, Neutral Beam and HHFW 
heated discharges on wall limiter start-up plasmas, lower single-null diverted plasmas, and double null diverted plasmas with and without $\mathrm{CHI}$.

Discharge reproducibility and performance are expected to be strongly affected by wall conditions. $\mathrm{CHI}$ discharges, for example, are initiated at mTorr pressures, with a 10-20 kA of injected current applied across the lower Divertor gap. This changes wall conditions significantly (wall gassing and erosion) from those required for Ohmic discharges. To date, the available conditioning methods have been bakeout to $309^{\circ} \mathrm{C}$, $\mathrm{D}_{2} \mathrm{GDC}$, and HeGDC. The final bakeout capability (November 2000) will allow heating of all graphite and CFC tiles to $350^{\circ} \mathrm{C}$ and the vacuum vessel to $150^{\circ} \mathrm{C}$. A Solid target Boronization (STB) probe has been installed and will be tested in summer, 2000. Other boronization methods such as glow discharge aided chemical vapor deposition using deuterated boron compounds will be tested (October 2000). Hydrogenated boron compounds will not be used in NSTX due to the HHFW need to avoid a hydrogen parasitic resonance.

In this paper, we describe ST Boundary Physics issues expected during NSTX high power long pulse operations (Sec.2), wall conditioning for First Plasma start-up in February 1999 with few internal components (Sec.3), wall conditioning for 1 MA Plasmas after August 1999 with full internal components (Sec.4), plasma operation results (Sec.5), wall evolution and surface analysis results (Sec.6) Summary and Conclusions (Sec.7).

\section{ST Boundary Physics Issues Expected During NSTX High Power, Long Pulse Operations}

NSTX is expected to produce plasma boundary regimes and plasma surface interactions similar to tokamaks but with significant differences.[1,2] Fig.2 shows how the ST magnetic field line geometry differs from that of a conventional large aspect ratio tokamak. The inboard plasma side is dominated by the toroidal field, while the outboard plasma side is dominated by a strong poloidal field component. This magnetic geometry results in an ST outboard plasma edge characterized by a short 
field line length in the unfavorable curvature region, and an inboard plasma edge characterized by a long field line length in the favorable curvature region. The dominant good field curvature of the inner region provides the ST with magnetohydrodynamic (MHD) stability at high plasma pressure in reduced magnetic field (high- $\beta$ ). [2]

Another consequence of the ST magnetic geometry shown in Fig.2 is that in inner-wall limited discharges, the field in the Scrape-Off Layer (SOL) varies by a factor of 4 and in diverted discharges by a factor of 2 . This results in large reflected and trapped ion flux in the SOL. This reflection of trapped ion flux increases the effective parallel connection length in a collisionless edge plasma. Collisions reduce the effect of this trapping. Since the width of the SOL is determined by the ratio of the parallel to perpendicular transport, the longer parallel connection length may cause a wider SOL in the ST as the edge plasma becomes less collisional. However, during Neutral Beam heating, under some conditions (e.g., lower $l_{p}$ ), substantial ion loss may occur from large ion orbits in the outer region of bad curvature which could increase the perpendicular transport and tend to shorten the SOL. In addition, on inner wall surfaces, flux expansion ratios of $\sim 10$ in the SOL for ST Inner Wall Limited discharges will lower the effective incident power densities. In the outer region, however, the field line pitch of about $45^{\circ}$ results in an short outer connection length from the midplane to the inner wall, and even shorter to the divertor plates for diverted discharges.

In NSTX, due to the low aspect ratio, the tokamak divertor figure of merit "P/R", the ratio of heating power to major radius, commonly used to compare devices of comparable cross-field transport and magnetic flux expansion, will be $\sim 2 x$ that of tokamaks. However, the effect of smaller major radius may be offset by effects discussed above which increase the power flux width. In HHFW heated discharges up to $6 \mathrm{MW}$ for pulse lengths of $5 \mathrm{sec}$, the ratio $P / R=7.1 \mathrm{~W} / \mathrm{m}$. When $5 \mathrm{MW} \mathrm{NBI}$ heated discharges are added, the peak injected powers approach $\sim 11 \mathrm{MW}$ and $\mathrm{P} / \mathrm{R} \sim 13$ $M W / m$. Simulations indicate $[3,4]$ that the incident power densities on the divertor 
plates of inner wall limiter discharges will be in the range 2.1 to $3.8 \mathrm{MW} / \mathrm{m}^{2}$. Similarly, the incident power densities on the divertor plates for double null diverted discharges are predicted to be in the range 4.4 to $7.2 \mathrm{MW} / \mathrm{m}^{2}$. Thermal response calculations $[3,4]$ for divertor tile, front face temperature rise indicate a peak temperature of $1200^{\circ} \mathrm{C}$ during a $5 \mathrm{sec}$ application of the highest estimated power density of $7.2 \mathrm{MW} / \mathrm{m}^{2}$. In the case of the Center Column, the peak incident power density for Inner Wall Limited discharges is expected to be $\sim 2 \mathrm{MW} / \mathrm{m}^{2}$. In the case of the Center Column tiles, which are not actively cooled, the expected tile front face surface temperature rise is $\leq$ $1000^{\circ} \mathrm{C}$ during a $5 \mathrm{sec}$ application of an incident power density of $2 \mathrm{MW} / \mathrm{m}^{2}$. Although these temperature rises are below the regime where radiation enhanced sublimation would be expected to instigate carbon blooms, this may no longer be the case as surfaces become micro-fractured and eroded due to intense ion bombardment. The application of additional heating power can be handled using shorter pulse lengths, but for longer discharges advanced heat-flux reduction techniques must be found.[2,3,4]

\section{Wall Conditioning for First Plasma Start-up in February 1999 with Few Internal Components}

The initial configuration for first plasma start-up in February 1999 consisted of the stainless steel vacuum vessel, the Center Column partially clad (50\%) with graphite, and a small graphite outer bumper limiter. The Passive Stabilizer Plates were not yet installed and there was no graphite on the Outer Divertors. The initial vessel evacuation started in mid November 1998. At that time the bakeout system was not functional. In order to remove water, $\mathrm{CO}, \mathrm{CO}_{2}$, and hydrocarbons as rapidly as possible so as to meet the start-up schedule, about 39 hours of $D_{2} G D C$ was performed at room temperature. This was followed by 4 hours of HeGDC to remove residual $D_{2}$. A preliminary GDC system was used for this process.[5] This consisted of a moveable Stainless Steel anode and a biased preionization filament for initiating GDC at the actual operating pressure and voltage (2mTorr for $D_{2}$ and $4 \mathrm{mTorr}$ for $\mathrm{He}$ at $400 \mathrm{~V}$ ). Starting at the actual operating pressure and voltage was done to reduce violent arcing and sputtering events, and to reduce stress on the torus vacuum pumping 
system which was kept in the normal high vacuum mode during GDC. Fig.3 shows a comparison of $D_{2} G D C$ wall impurity cleaning followed by HeGDC wall conditioning to remove the residual $D_{2}$. It is seen that $D_{2} G D C$ was very effective for removing impurities from the walls. HeGDC was found much less efficient for removing impurities but was found very effective for removing residual $D_{2}$. The First Plasma discharge was limited to about $20 \mathrm{kA}$. Subsequently, the biased preionization filament was applied to assist plasma breakdown, and over a 1.5 day period, discharges were readily obtained up to $280 \mathrm{kA}$ with about $1 / 3$ of the available $\mathrm{OH}$ flux.

\section{Wall Conditioning After August 1999 for 1 MA Plasmas with Full Internal Components}

After a 5 month opening to install additional hardware, NSTX was evacuated in early August 1999 with a nearly complete internal configuration (i.e., as shown in Fig. 1) which included a divertor region clad $100 \%$ with graphite tiles, and copper Passive Stabilizer plates clad about $50 \%$ with graphite tiles. Other internal hardware installations included a double fixed anode GDC system with two biased filaments which allows GDC initiation at the operating pressure and voltage.[5] In view of the extensive construction that had taken place in the vessel during the 5 month vent, and the need to quickly remove residual impurities, about 140 hours of $D_{2} G D C$ was performed at room temperature to remove water, $\mathrm{CO}, \mathrm{CO}_{2}$, and hydrocarbons, and about 20 hours of HeGDC to remove residual $D_{2}$. This was followed by a $206^{\circ} \mathrm{C}$ bakeout of the Center Column performed using resistive heating, during which 10 hours of $D_{2} G D C$ and 12 hours of. HeGDC were performed. In September 1999, operations resumed, and plasma discharges of over $800 \mathrm{kA}$ were achieved relatively quickly. Two additional bakeout experiments were performed at increasing higher temperatures; during the last bakeout in November 1999, the Center Column was heated to $309^{\circ} \mathrm{C}$ and the Passive Stabilizer to about $220^{\circ} \mathrm{C}$. Fig. 4 shows the vessel base pressure and the partial pressures of the mass $18,28,32$, and 44 impurity components. 
During this $D_{2} G D C$ and HeGDC cleaning procedure, the vessel windows were not covered. The light transmission of an exposed midplane window near a GDC wall anode was measured after GDC, bakeout, and low Ohmic power plasma operations (Ip $\leq 500 \mathrm{kA}$ ). The transmission in the visible was found to decrease about $5 \%$ per 10 hours of $D_{2}$ or $\mathrm{He}$ GDC at room temperature. Measurements of the thickness and elemental composition of the coating on an exposed window indicated that the depositions prior to $\mathrm{CHI}$ and Ohmic discharges with $\mathrm{Ip}>0.5 \mathrm{MA}$ was $\sim<50 \AA$ thick with the following composition: $\mathrm{H}(18.3 \%), \mathrm{C}(15.0 \%), \mathrm{O}(24.0 \%), \mathrm{Cr}(5.5 \%), \mathrm{Fe}(23.0 \%), \mathrm{Cu}$ (12.0\%), and Mo $(0.20 \%)$. No deuterium was observed even though only deuterium plasmas were used (no hydrogen plasmas were ever used). Hence, the hydrogen content is attributed to hydrogenated components residual in the tiles which outgasssed during discharges. Relatively little carbon was observed even though there was an extensive graphite surface. The deposition appeared to be mostly metal oxides. Visible window transmissions measured at other toroidal locations increased systematically as the distance from the GDC wall anodes increased, indicating some enhanced local deposition near the GDC anodes.

\section{Plasma Operation Results}

The experimental campaign achieved about 1125 discharges, during 41 plasma operation days with nearly 30 discharges per day. After the final bakeout in November 1999, improved wall conditions and advances in control technique allowed higher current discharges to $I_{p}>0.9 \mathrm{MA}$ for $70 \mathrm{~ms}\left(\mathrm{~W}_{\mathrm{tot}}=31 \mathrm{~kJ}, \beta_{\mathrm{t}}=5.6 \%, \tau_{\mathrm{e}}=15 \mathrm{~ms}\right.$, $\mathrm{n}_{\mathrm{e}} \sim \leq 2.8 \times 10^{13} \mathrm{~cm}^{-3}$ ), and by December 14, 1999, 1 MA discharges were attained with ramp-rates of up to $7 \mathrm{MA} / \mathrm{sec} .[6,7] \mathrm{In}$ these discharges, Electron Cyclotron Preionization ( $18 \mathrm{GHz}, 30 \mathrm{~kW}$ ) and biased filament preionization was used routinely to assist discharge initiation. Plasma position was controlled in the feedback mode. Early in the current rise phase, at ramp rates greater than about $5 \mathrm{MA} / \mathrm{sec}, \mathrm{MHD}$ activity often occurred which exhibited coherent Mirnov oscillations of decreasing frequency indicative of possible locked tearing modes. In the flattop region, stored energy and plasma beta increased with plasma current. Late in the discharge, reconnection 
events were often observed as the loop voltage decreased. In general, these initial results suggest that heating during the initial $l_{p}$ ramp will be important for achieving longer pulse discharges.[7]

$\mathrm{CHI}$ discharges were obtained up to $130 \mathrm{kA}$ with $\mathrm{CHI}$ injected currents of $20 \mathrm{kA}$ for $\sim 500 \mathrm{~V}$ bias yielding current multiplications off 6-7. In some experiments, current multiplications up to 10 were obtained. Stable high current discharges were produced for up to $130 \mathrm{~ms}$ for some discharges. $\mathrm{CHI}$ discharges were demonstrated with fast puff Divertor region $D_{2}$ pressures from 16 mTorr down to 1 mTorr. The $\mathrm{CHI}$ ceramic insulators in the divertor gaps performed satisfactorily through the campaign. However, evidence of arcing and depositions in the insulator regions suggested improvements for additional insulator protection and metallic impurity reduction.[8]

The RF antenna system was vacuum conditioned to $25 \mathrm{kV}$. During plasma operations, good antenna plasma matching was achieved with 8 antennas and two transmitters, and a reactive shift with plasma edge location was observed. No significant parasitic loading was observed. $2 \mathrm{MW}$ of HHFW power was injected into Ohmic target plasmas, and an increase in plasma energy was observed. Soft $x$-ray spectra showed centrally peaked electron heating during a modulation experiment using $0-\pi-0-\pi$ phasing to yield the slowest phase velocity; the $0-\pi-\pi-0$ phasing did not exhibit heating, and this observed phase dependence is under investigation. HHFW antenna structures (e.g., BN shields) performed well at $2 \mathrm{MW}$ and in the edge plasmas of high current discharges.[9]

\section{Wall Evolution and Surface Analysis Results}

During Ohmic operations, about 40 discharges were required to achieve low reproducible $D_{\alpha}$ edge light emission. In general, the application of HeGDC between

discharges had no systematic impact on plasma recycling and plasma performance in the flat-top region. However, HeGDC was useful if the plasma had start-up problems. In special cases, for example, following initial $\mathrm{CHI}$ experiments, 30 minutes of HeGDC 
was performed, and it then took $\sim 10$ single-null discharges to reduce visible light emission from $D_{\alpha}$, carbon, and oxygen back to pre-CHI levels. After this, performing 5 minutes of HeGDC between discharges made a step change $(-10 \%)$ to achievable plasma current and/or flattop duration; subsequent 5 minute HeGDC between discharges exhibited no improvement in plasma performance. In other discharge sequences, the recycling/visible light baseline was reduced by only up to $10 \%$ after 3 HeGDC /plasma discharge sequences (Fig.5). The $\left(H_{\alpha} / H_{\alpha}+D_{\alpha}\right)$ ratio, which is important to minimize in NSTX so as to avoid parasitic HHFW resonance, was about $95 \%$ before the October 1999 bakeout but reached less than $10 \%$ by the end of the campaign during gas puffed discharges. Initial visible spectroscopic measurements indicated moderate levels of low- $Z$ impurities that tended to increase with discharge number during a given operating day. Bolometer measurements on similar discharges indicated radiative power fractions in the range 0.25-0.30. However, in other discharges, filtered Soft-Xray measurements of plasma profiles indicated that metallic impurities due to exposed copper and stainless steel were often high.[10]

Four stainless steel and two silicon sample coupons $(2.5 \mathrm{~cm} \times 2.5 \mathrm{~cm})$ were mounted at the midplane at four toroidal locations on the outer vessel wall about $10 \mathrm{~cm}$ beyond the SOL of the most outward plasma. In addition, 12 stainless steel coupons were positioned in a Poloidal Array at one toroidal location in a Passive Stabilizer gap, about $4 \mathrm{~cm}$ beyond the major radius of the graphite tiles on the plasma facing side of the Passive Stabilizers. Each of the stainless steel coupons was partially coated with a $0.4 \mu \mathrm{m}$ layer of graphite so as to provide measurements of both deposition and erosion. Deuterium implanted from the plasma in the carbon of the coupons was consistent with saturation by particles of a few hundred eV.[11] The change in carbon thickness was measured using a $1.5 \mathrm{MeV}$ proton Rutherford Back-scattering Spectroscopy (RBS) before and after plasma exposure.[11] The results indicate net carbon erosion of all coupons. In the case of the Poloidal Coupon Array, more carbon erosion occurred on the lower Passive Plate $(0.17-0.25 \mu \mathrm{m})$ than on the upper Passive Plate $(0.02-0.1 \mu \mathrm{m})$ coupons. In the case of the Toroidal Coupon Array, on the outer 
vessel wall, the carbon erosion varied from $\sim 0.06 \mu \mathrm{m}$ to $\sim 0.33 \mu \mathrm{m}$.[11] This toroidal asymmetry may be related in part to the shadowing and reflection effects of nearby hardware. Erosion of wall coupons was also observed on JET and attributed to effect of charge exchange neutrals.[12] Metal deposition (mainly $\mathrm{Fe}$ and $\mathrm{Cu}$ ) was found on all coupons. In the case of the Poloidal Coupon Array, more metal was found on the lower Passive Stabilizer coupons $\left(1.2-1.5 \times 10^{17} / \mathrm{cm}^{2}\right)$ than on the upper $\left(\sim 0.5 \times 10^{17} / \mathrm{cm}^{2}\right) .[11]$ This asymmetry may be attributable to the effect of the first $\mathrm{CHI}$ plasma experiments which were initiated across the lower Divertor gap region; single null Ohmic plasma discharges may have also contributed.

$2 \mathrm{MeV}{ }^{4} \mathrm{He}$ RBS and Electron Microscopy were used to measure metal deposition on four lower Passive Plate graphite tiles.[11] $\mathrm{Fe}$ and $\mathrm{Cu}$ were observed in rough areas (local depressions) on the plasma facing surfaces at $\sim 2 \times 10^{17} / \mathrm{cm}^{2}$, similar to the metal coverage on the lower Passive Stabilizer coupons.

Center Column erosion was studied by implanting two Center Column tiles (one graphite and one CFC) with $300 \mathrm{keV} \mathrm{Si} \mathrm{to} \mathrm{a} \mathrm{depth} \mathrm{of} 0.34 \mu \mathrm{m}$. Ion Beam analysis was performed before and after exposure to NSTX plasmas during the August 1999 Experimental Campaign. $2 \mathrm{MeV}{ }^{4} \mathrm{He}$ RBS measurements found the Si markers to be absent, thereby indicating net erosion exceeding $>0.4 \mu \mathrm{m}$. In addition, metallic deposition of $0.13 \times 10^{17} / \mathrm{cm}^{2}$ was found on the graphite tile and $0.48 \times 10^{17} / \mathrm{cm}^{2}$ on the CFC tile which is about $10 x$ less metal than deposited on the outer wall coupons and passive plate tiles.[11] This difference may be due to higher erosion rates on the Center Column than on outer coupons which were more distant from the plasma edge.

There was no macroscopic damage to the graphite tiles of the Center Column, inner and outer Divertors, and the Passive Plates other than symmetric discoloration on plasma-facing, power-absorbing surfaces and a few arc spots. In general, the visible changes to these plasma facing surfaces were toroidally symmetric but different for the lower and upper Divertors. The lower outer Divertor exhibited thermal 
deposition pattern extending from the Divertor gap to its major radius center, however, the upper outer Divertor tile surfaces exhibited a more centralized thermal deposition pattern. The upper Divertor pattern may be indicative of normal double null Ohmic plasma depositions, whereas the lower Divertor pattern may be due to the sum effects of single null plasmas, double null plasmas, and $\mathrm{CHI}$ startup across the lower Divertor gap region.

In contrast to the graphite tile surface changes described above, the CFC tiles exhibited from about 2 to 8 , horizontal damage tracks per tile. These tracks have the visual appearance of cracks but were actually shallow tracks about $0.1 \mathrm{~cm}$ wide by $0.01 \mathrm{~cm}$ deep and varying in length from about $0.5 \mathrm{~cm}$ to $3 \mathrm{~cm}$. Some tracks are uniformly deep, others appear to be a series of pits. The axes of these tracks seem parallel to the carbon fibers embedded in the CFC material. Indeed the tiles were machined so that the CFC fibers were oriented parallel to the plasma facing side. However, due to the curvature of the tile surface, fiber ends appeared at the surface. These exposed ends of near surface fibers may have accelerated the erosion of fibers. In addition, micro-stresses in thin layers covering near-surface produced by machining may have caused some fibers to fracture under cyclic thermal stress. In the case of a typical track size of $0.5 \mathrm{~cm}$ long by $0.1 \mathrm{~cm}$ wide by $0.01 \mathrm{~cm}$ deep, a typical track volume of $\sim 5 \times 10^{-4} \mathrm{~cm}^{3}$ would have released about $1 \mathrm{mg}$, or $5 \times 10^{19}$ atoms of carbon into the plasma edge. This CFC behavior will be monitored during forthcoming NBI operations which will result in much higher power loading on these tiles.

The $\mathrm{CHI}$ ceramic insulators in the divertor gaps performed satisfactorily through the campaign. However, evidence of arcing and depositions in the insulator regions suggested improvements for additional insulator protection and metallic ( $\mathrm{Fe}$ and $\mathrm{Cu}$ ) impurity reduction.[8]

\section{Summary and Conclusions}

NSTX started plasma operations in February 1999. NSTX has a sound design, and has achieved design goals on or ahead of schedule. The available wall 
conditioning included bakeout, $D_{2} G D C$, and HeGDC, and was applied to achieve 280 KA discharges in February 1999 with few internal components, 1 MA discharges in December 1999 with full internal components, and 0.5 pulse lengths. $D_{2} G D C$ was found to be more effective at evolving water and hydrocarbons than HeGDC. HeGDC was found to be effective for removing remaining $D_{2}$. Inter-shot HeGDC allows fast recovery from an air vent, and $\mathrm{CHI}$ discharges. Inter-discharge HeGDC does not routinely improve performance; this may be due to the need for yet cleaner wall conditions. Net non-uniform carbon erosion and metal deposition ( $\mathrm{Cu}$ and $\mathrm{Fe}$ ) on Passive Stabilizer Plate and midplane wall coupons. Heavier depositions were observed in the lower half of the vessel. This suggests $\mathrm{CHI}$, which was initiated across the lower Divertor gap, was the source for this asymmetry rather than GDC or plasma discharges.

ST's are compact devices with high expected heat flux. Wall conditioning techniques are and will be essential. The forthcoming upgrades and Research Plan include increasing Passive Stabilizer Plate graphite coverage from $50 \%$ to $100 \%$, enhanced bakeout capability, Solid Target and Deuterated Boronization, $5 \mathrm{MW}$ NBI (available October 1999), VUV spectroscopy, Visible Bremsstrahlung $\left(Z_{\text {eff }}\right)$, Thomson Scattering and CHERS diagnostic systems. Boundary physics research in 2000-2001 will focus on the effect of wall conditioning on reproducibility, $\tau_{E}$ and edge density, temperature, and pressure gradients, and initial heat flux scaling experiments with new Infrared Television Cameras. 


\section{Acknowledgments}

We wish to acknowledge the technical contributions of M. Anderson, R. Cutler, T. Czeizinger, G. D'Amico, M. Dimattia, S. Edwards, R. Gernhardt, L. Guttadora, T. Holoman, T. Provost, J. Sorensen, J. Timberlake, J. Winston, and the NSTX support and operating Staffs. This work is supported by U. S. DoE Contracts DE-AC0276CH03073, DE-AC05-96OR22464, DE-AC05-00R22725, DE-FG02-99ER54524, and DE-AC04-94AL85000.

\section{References}

1. Y-K. M. Peng and D. Strickler, Nucl. Fusion, 26, (1986) 769.

2. S.M. Kaye, et al., Fus. Technol. 36, (1999) 16, and references therein.

3. R. Maingi, Proc. Int. Workshop ST's, Abingdom, United Kingdom, 1996.

4. R. Maingi, Proc. Int. Workshop ST's, St. Petersburg, Russia, 1997.

5. H. W. Kugel, et al., Proc. of the 18th Symposium On Fusion Engineering, Albuquerque, NM, October 25-29, 1999, (IEEE, 1999) 296.

6. M. Bell, et al., to appear in Proc. of the European Physical Society Conference on Controlled Fusion and Plasma Physics, Budapest, Hungary, June 12-16, 2000. 7. J. Menard, et al., to appear in Proc. of 18th IAEA Fusion Energy Conference, Sorrento, Italy, Oct.4-10, 2000.

8. R. Raman, et al., to appear in Proc. of 18th IAEA Fusion Energy Conference, Sorrento, Italy, Oct.4-10, 2000.

9. J. R. Wilson, et al., to be published.

10. D. Stutman, et al., Bull. A. Phys. Soc. 44(7), (1999) 187.

11. W. Wampler, et al., to be published.

12. M. Mayer, et al., J. Nucl. Mater, 266-269 (1999) 604. 


\section{Figure Captions}

Fig.1 Partial schematic cross section of the NSTX device.

Fig.2 Schematic of Spherical Torus (ST) magnetic field line geometry.

Fig.3 Comparison of $\mathrm{D}_{2} \mathrm{GDC}$ impurity cleaning followed by HeGDC wall conditioning for February 1999 vessel configuration with few internal components. The vertical arrows indicate the start of each $D_{2} G D C$ application after a period of no GDC. $D_{2} G D C$ was very effective for removing impurities from the walls. HeGDC was used to remove residual $D_{2}$.

Fig.4 Vessel base pressure behavior and the partial pressures of the mass 18, 28, 32 , and 44 impurity components as walls were conditioned using $D_{2} G D C, H e G D C$, and bakeout to prepare NSTX for 1 MA Discharges with full internal hardware.

Fig.5 Edge luminousity behavior of $\mathrm{Da}_{a}$ and $\mathrm{He} / \mathrm{l}$ for $\mathrm{HeGDC}$ sequences (refer to text). 


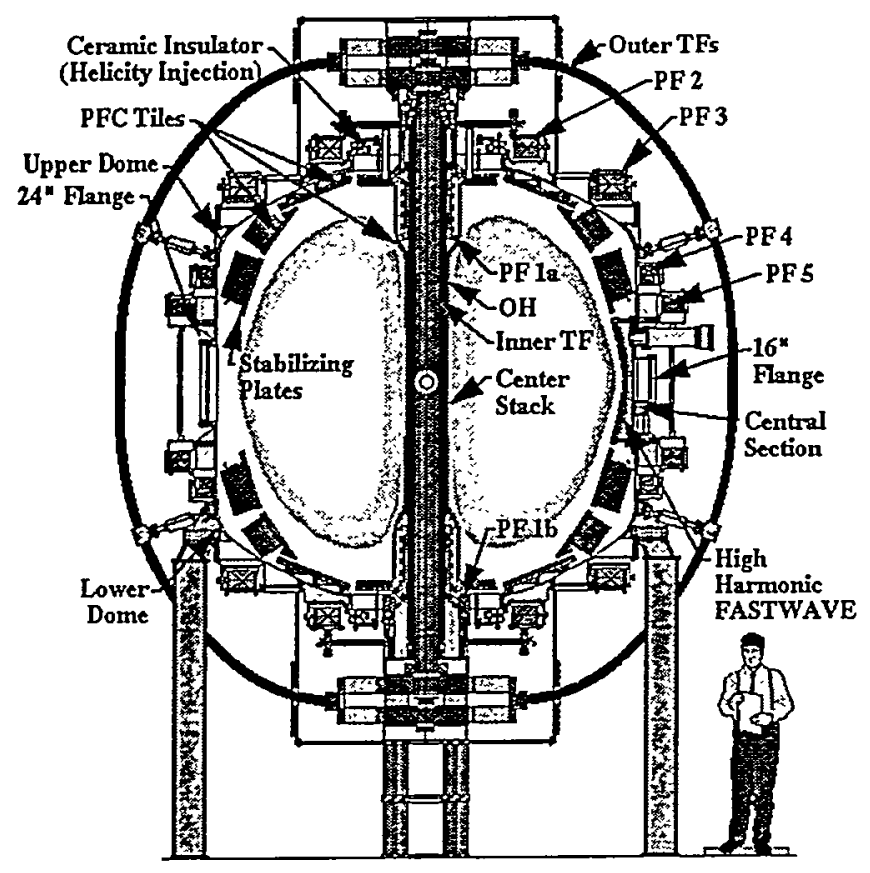

Fig. 1 Partial schematic cross section of the NSTX device. 


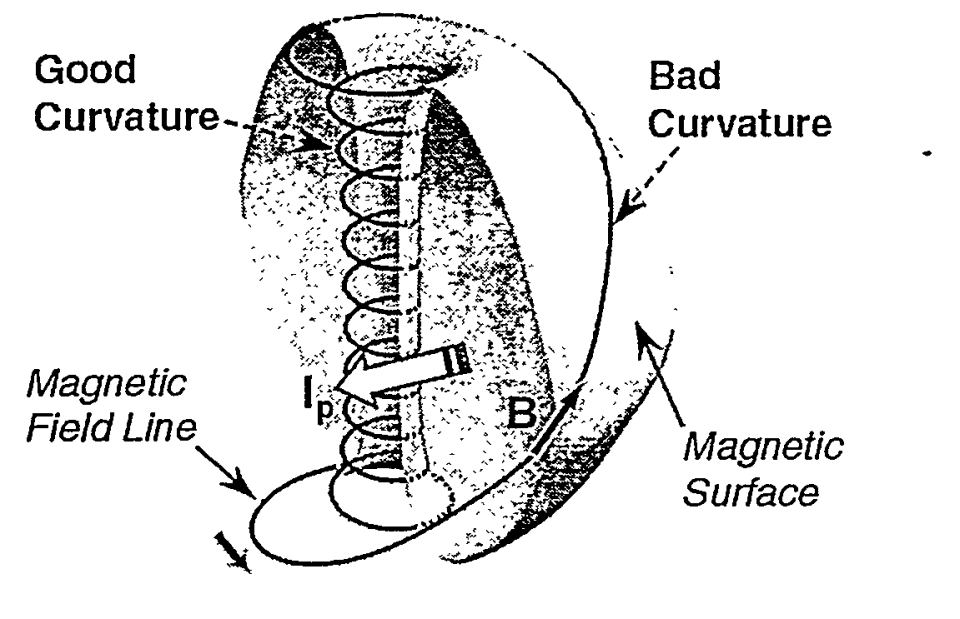

Fig.2 Schematic of Spherical Torus (ST) magnetic field line geometry. 


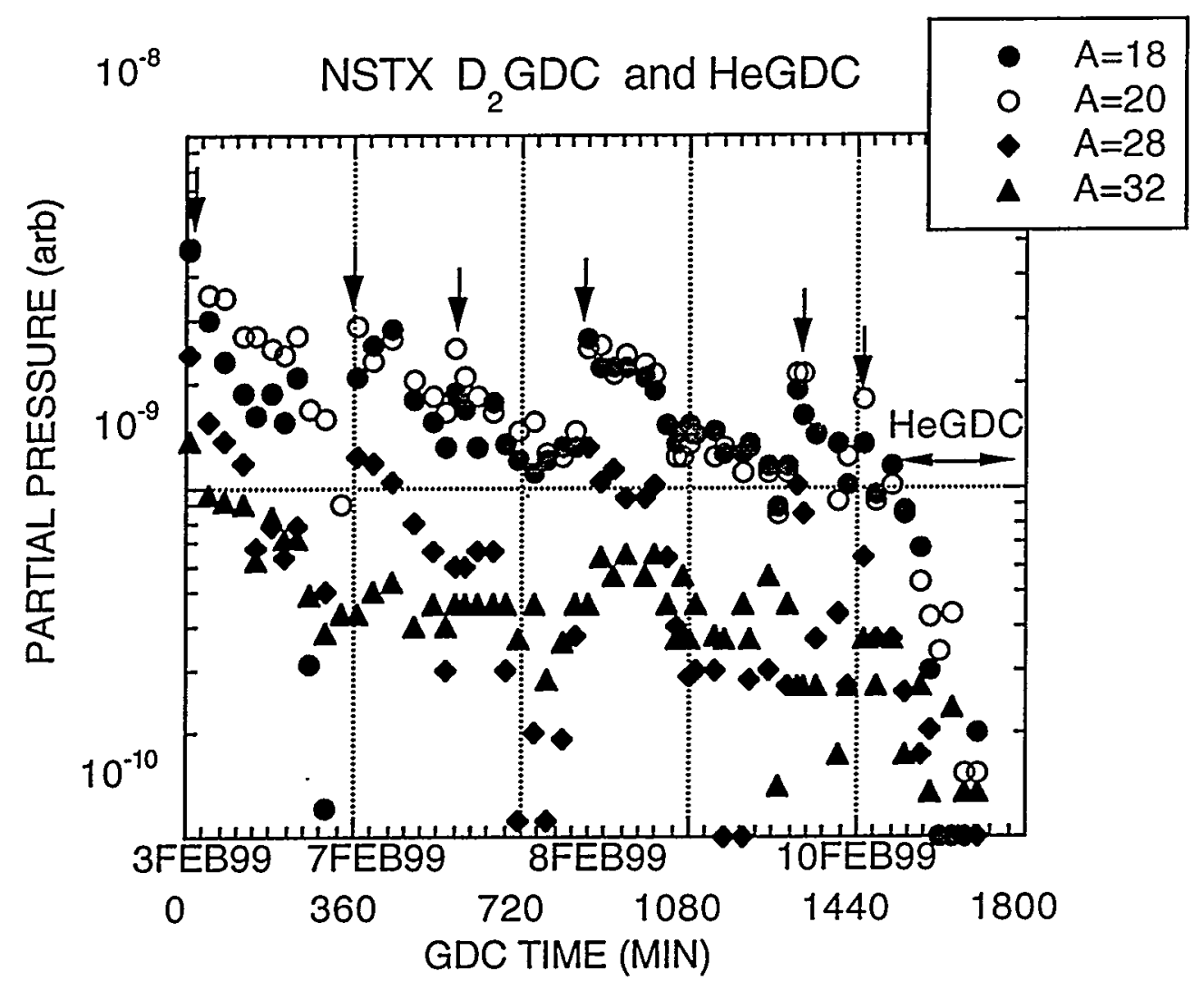

Fig.3 Comparison of $D_{2} G D C$ impurity cleaning followed by HeGDC wall conditioning for February 1999 vessel configuration with few internal components. The arrows indicate the start of each $D_{2} G D C$ application after a period of no GDC. $D_{2} G D C$ was very effective for removing impurities from the walls. HeGDC was used to remove residual $D_{2}$. 


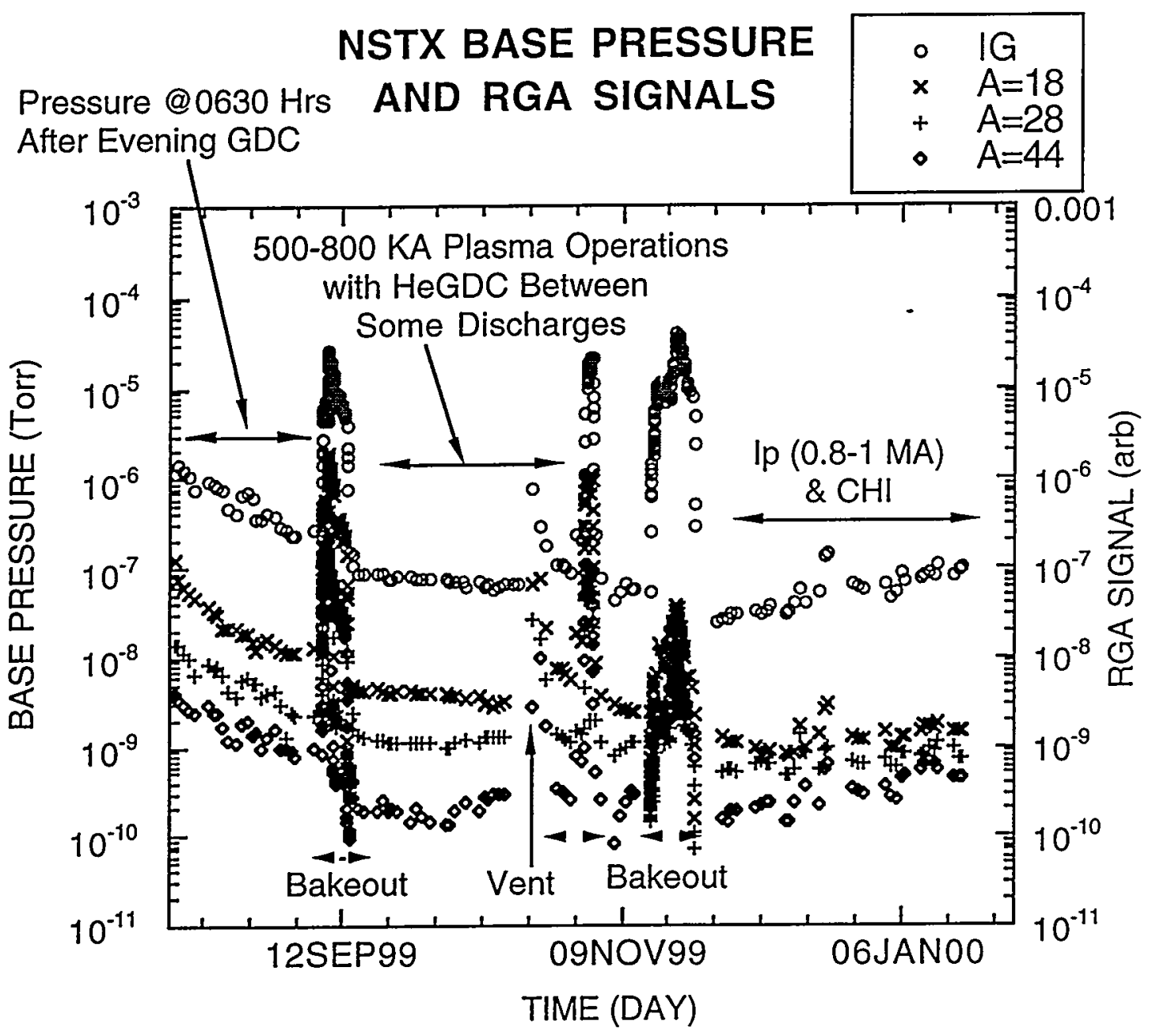

Fig.4 Vessel base pressure behavior and the partial pressures of the mass 18, 28, 32, and 44 impurity components as walls were conditioned using $D_{2} G D C, H e G D C$, and bakeout to prepare NSTX for 1 MA Discharges. 

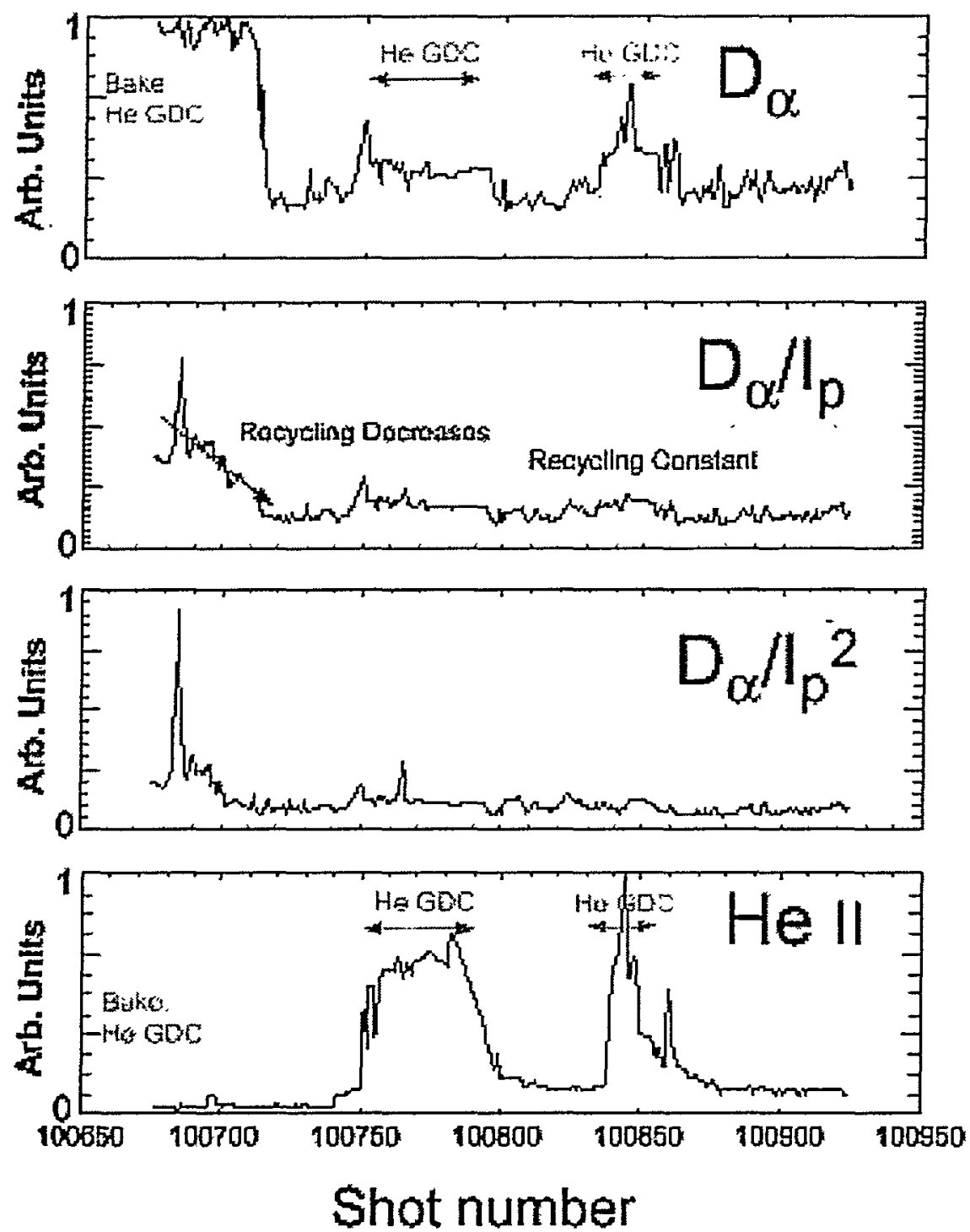

Fig.5 Edge luminousity behavior of $D_{a}$ and Hell for HeGDC sequences (refer to text). 